\title{
The light's in my eyes: optical modeling demonstrates wind is more important than sea surface-reflected sunlight for foraging herons
}

\author{
Holly Milton Brown ${ }^{\text {Corresp., } 1}$, Margaret Rubega ${ }^{1}$, Heidi Dierssen ${ }^{2}$ \\ 1 Department of Ecology and Evolutionary Biology, University of Connecticut, Storrs, CT, United States \\ 2 Department of Marine Sciences, University of Connecticut at Avery Point, Groton, CT, United States \\ Corresponding Author: Holly Milton Brown \\ Email address: holly.k.brown@uconn.edu
}

Multiple lineages of birds have independently evolved foraging strategies that involve catching aquatic prey by striking at them through the water's surface. Diurnal, visual predators that hunt across the air-water interface encounter several visual challenges, including sun glint, or reflection of sunlight by the water surface. Intense sun glint is common at the air-water interface, and it obscures visual cues from submerged prey. Visually-hunting, cross-media predators must therefore solve the problem of glint to hunt effectively. One obvious solution is to turn away from the sun, which would result in reduction of glint effects. However, turning too far will cast shadows over prey, causing them to flee. Therefore, we hypothesized that foraging herons would orient away from, but not directly opposite to the sun. Our ability to understand how predators achieve a solution to glint is limited by our ability to quantify the amount of glint that free-living predators are actually exposed to under different light conditions. Herons (Ardea spp.) are a good model system for answering questions about cross-media hunting because they are conspicuous, widely distributed, and forage throughout a variety of aquatic habitats, on a variety of submerged prey. To test our hypothesis, we employed radiative transfer modeling of water surface reflectance, drawn from optical oceanography, in a novel context to estimate the visual exposure to glint of free-living, actively foraging herons. We found evidence that Ardea spp. do not use body orientation to compensate for sun glint while foraging and therefore they must have some other, not yet understood, means of compensation, either anatomical or behavioral. Instead of facing away from the sun, herons tended to adjust their position to face into the wind at higher wind speeds. We suggest that radiative transfer modeling is a promising tool for elucidating the ecology and evolution of air-towater foraging systems. 
1 The light's in my eyes: optical modeling demonstrates wind is more important than sea surface-reflected sunlight for foraging herons

4 Holly Milton Brown ${ }^{1}$, Margaret Rubega ${ }^{1}$, and Heidi M. Dierssen ${ }^{2}$

$5 \quad{ }^{1}$ Department of Ecology and Evolutionary Biology, University of Connecticut, Storrs, CT

6 06269, USA

$7 \quad 2$ Department of Marine Sciences, University of Connecticut, Groton, CT 06340, USA

8

9 Corresponding Author:

10 Holly Milton Brown ${ }^{1}$

11 Current Address: Walter Reed Army Institute of Research, 503 Robert Grant Ave., Silver Spring,

12 MD 20910

13 Email: holly.k.brown@uconn.edu

19 Abstract 
20 Multiple lineages of birds have independently evolved foraging strategies that involve catching

21 aquatic prey by striking at them through the water's surface. Diurnal, visual predators that hunt

22 across the air-water interface encounter several visual challenges, including sun glint, or

23 reflection of sunlight by the water surface. Intense sun glint is common at the air-water interface,

24 and it obscures visual cues from submerged prey. Visually-hunting, cross-media predators must

25 therefore solve the problem of glint to hunt effectively. One obvious solution is to turn away

26 from the sun, which would result in reduction of glint effects. However, turning too far will cast

27 shadows over prey, causing them to flee. Therefore, we hypothesized that foraging herons would

28 orient away from, but not directly opposite to the sun. Our ability to understand how predators

achieve a solution to glint is limited by our ability to quantify the amount of glint that free-living

30 predators are actually exposed to under different light conditions. Herons (Ardea spp.) are a

31 good model system for answering questions about cross-media hunting because they are

32 conspicuous, widely distributed, and forage throughout a variety of aquatic habitats, on a variety

33 of submerged prey. To test our hypothesis, we employed radiative transfer modeling of water

34 surface reflectance, drawn from optical oceanography, in a novel context to estimate the visual

35 exposure to glint of free-living, actively foraging herons. We found evidence that Ardea spp. do

36 not use body orientation to compensate for sun glint while foraging and therefore they must have

37 some other, not yet understood, means of compensation, either anatomical or behavioral. Instead

38 of facing away from the sun, herons tended to adjust their position to face into the wind at higher

39 wind speeds. We suggest that radiative transfer modeling is a promising tool for elucidating the

40 ecology and evolution of air-to-water foraging systems. 
43 Birds have repeatedly, and independently, evolved foraging strategies that involve detecting prey

44 in water, and striking at them through the air-water interface. To do so successfully, they must

45

46

47 contend with a number of visual challenges imposed by the optical properties of the water itself. First, water surfaces can reflect light. Sun glint (hereafter, "glint") refers to the reflection of sunlight by a water surface, directly toward the viewer (Hochberg et al., 2011; Preisendorfer \& Mobley 1986). Glint obscures detection of upwelling light from beneath the surface of the water, making it more difficult to see objects below the surface. Humans experience glint as visible bright spots on the surface of the water. Glare is the visual discomfort from the direct reflection of the sun light into their eyes (e.g., Signoroni et al., 2020).

Cross-media predators, by definition, are attempting to locate submerged prey, and therefore we expect them to have evolved ways to compensate for the effect of glint. One obvious method of reducing the effect of glint is to turn away: an animal that forages at the air-water interface should orient itself generally away from the sun under clear sky conditions if it aims to reduce visual exposure to glint. But by how much? The amount of glint exposure is a complex function of the viewing direction, field of view of the detector or eye, topography of a wind-blown sea surface, sun elevation and the spectral distribution of light.

Radiative transfer modeling, used in optical oceanography, has shown that glint is generally reduced with an increasing difference in bearing from the sun (Mobley, 1999). For example, assuming $5 \mathrm{~m} / \mathrm{s}$ wind, a sun elevation of $60^{\circ}$, and a viewing angle looking $40^{\circ}$ downward with respect to the horizon, the sea surface would reflect only about $3 \%$ of the skylight incident upon 
65 the sea surface for an animal viewing the sea surface facing directly opposite $\left(180^{\circ}\right)$ to the sun's

66 bearing. This percentage remains fairly similar until the viewer is facing perpendicular $\left(90^{\circ}\right)$ to

67 the sun's bearing, but begins to rise fairly quickly thereafter, to about $12 \%$ when facing directly

68 into the sun's bearing (Fig. 7 in Mobley, 1999). Under higher wind conditions and/or when the

69 sun is directly overhead (sun elevation $90^{\circ}$ ), orientation plays less of a role in reducing glint

70 (Zhang et al. 2017).

However, aquatic birds that hunt during the daytime must compensate for an additional

challenge: they must be within striking distance of their prey without causing prey to flee. Even though glint is lowest at $180^{\circ}$ to the sun's bearing, this is also the bearing that would cause a predator to hunt directly into its own shadow. Several aquatic prey species are known to flee when shadows pass overhead (e.g., Forward, 1977; Roberts, 1978; Yoshizawa \& Jeffery 2008). Therefore, a bird hunting across the air-water interface on a sunny day is likely trading off its ability to see prey against the prey's ability to see them.

Mobley (1999) used radiative transfer modeling to show that when orienting a light detector at about $135^{\circ}$ away from the bearing of the sun while measuring remote sensing reflectance of oceanic environments, the view of glint from the water surface is as low as possible over a wide range of water surface and environmental conditions, without facing directly into self-shadow. When the sun is overhead, however, orientation does not play a role in reducing glint. Mobley's work, by extension, suggests that although there is a range of orientations at which birds could reduce their exposure to glint, orienting at $135^{\circ}$ to the bearing of the sun is the position in which 
87 birds hunting across the air-water interface can best trade off reducing glint exposure, while also avoiding casting shadows over potential prey. This logic assumes that birds see and perceive glint as we do, an assumption that may not be justified, given the limitations on what we know about avian vision. Nonetheless, there is some limited, and anecdotal evidence that they do and that they may be trading off glint exposure against their own detectability as we predicted based on Mobley’s (1999) radiative transfer modeling. For example, Brown Pelicans (Pelecanus occidentalis), were found to orient at an average of $135.6^{\circ}$ to sun bearing $\left(\mathrm{s} . \mathrm{d} .=36.1^{\circ}\right)$ as they dove for fish (Carl, 1987). We have also documented that a tern diving for fish in a pond, did so at about $140^{\circ}$ to sun bearing, (documented on video three times in a row; it also did so several times in a row before the lead author started recording the behavior; Supplemental Video 1). Even the behavior of non-aquatic avian predators suggests that they experience challenges from intense light conditions as we do. When the dark facial masks on Masked Shrikes (Lanius nubicus) were painted white, they oriented away from the sun to a greater degree than shrikes with black masks (Yosef, Zduniak \& Tryjanowski, 2012. ), suggesting that sunlight reflecting from their facial feathers caused some visual discomfort.

Visual ecologists have demonstrated that orientation is important in visual function (e.g., Muheim, Phillips \& Åkeesson, 2006; Penacchio et al., 2015), but there are only a handful of studies that investigate orientation specifically with regard to hunting strategies (Carl, 1987; King \& LeBlanc, 1995; Yosef, Zduniak \& Tryjanowski, 2012.; Huveneers et al., 2015). Orientation with respect to the sun may affect the ability to see prey, and therefore should be explicitly considered when studying the foraging ecology of visual, cross-media predators. Here, we examine the hypothesis that avian cross-media predators use body orientation to reduce glint 
110 in their strike zones while hunting, and that they do so in a manner that trades off glint exposure

111 against self-shadow into their strike zones (Fig. 1). To test this hypothesis, we studied diurnal

112 herons of the genus Ardea, which belong to a clade of piscivorous birds that have been

113 specializing to hunt across the highly reflective air-water interface for over 50 million years

114 (Prum et al., 2015).

115

116 We studied, specifically, two daytime-active herons, Great Blue Herons (Ardea herodias) and

117 Great Egrets (Ardea alba; hereafter, "herons"). These species are good models for answering

118 questions about cross-media hunting because they are numerous, conspicuous, widely

119 distributed, and forage throughout a variety of aquatic habitats, on a variety of submerged prey.

120 If herons were using orientation to trade off glint and self-shadow, we predicted that they would:

121 a. orient in ways that minimize glint, and maximize the signal from upwelling light (i.e., the light

122 reflected by potential submerged prey items), as compared with what would be expected if heron

123 orientation were random, and b. specifically, we expect them to orient at an average of $135^{\circ}$ to

124 the sun bearing. Great Blue Herons tend to be slightly more crepuscular than the more diurnal

125 Great Egrets (McNeil, Benoît \& DesGranges, 1993). In gathering data from both, our intent was

126 to obtain generalizable information about how herons might compensate for glare while hunting

127 through the air-water interface, over a wide range of daylight conditions. We employed radiative

128 transfer modeling in a novel context to directly estimate the actual exposure of individual birds

129 to glint, on the basis of their orientation to the sun, the sun elevation, and light conditions. 
131 We also considered the hypothesis that heron body orientation could be related to wind.

132 Orientation with respect to both sun position and wind direction have been widely recognized as

133 important physiological mechanisms by which animals regulate body and microhabitat

134 temperatures (e.g., Orr, 1970; Walsberg, 1993; Fortin Larochelle \& Gauthier, 2000; and many

135 others). If herons were orienting to prevent loss of body heat, we predicted that heron orientation

136 would correlate with wind direction, particularly at higher wind speeds. In addition, because of

137 light reflecting from differently oriented wave facets, the advantages of orienting away from the

138 sun are also reduced under higher wind speeds compared to flat conditions. Hence, we predicted

139 that they would be more likely to face into the wind, regardless of sun position, as wind speed

140 increased.

141

142 Materials \& Methods

143 In June 2013, January 2014, and January-February 2015, we opportunistically obtained 279

144 observations of 68 free-living, foraging herons in southern Florida (Fig. 2). As our study

145 involved focal animals in the field, it was not possible to record data blind. In areas where an

146 individual heron seemed to be actively guarding a foraging area (e.g., by chasing other

147 individuals away), we sampled the site only once. However, in areas where there were several

148 herons foraging, we were able to obtain observations of different individuals at the same

149 location. From a minimum distance of 20m, using binoculars (Nikon Monarch 3, 10x42), we

150 observed individual foraging herons, and recorded up to 6 instantaneous samples of their body

151 and head orientations, or fewer, if the individual flew away. In 2013, instantaneous samples were

152 spaced 5 minutes apart, while in 2014 and 2015 samples were taken every two minutes. At the

153 beginning of each observation, we noted the date, time, and the species. We noted sun visibility

PeerJ reviewing PDF | (2018:02:25602:1:1:NEW 21 Jul 2021) 
154 and cloud cover, as our predictions depended on the sun's being visible. We also noted wind 155 bearing and speed category: calm/virtually undetectable (approximately $0 \mathrm{~m} / \mathrm{s}$ ); leaves rustle 156 (approximately $5 \mathrm{~m} / \mathrm{s}$ ); branches sway (approximately $10 \mathrm{~m} / \mathrm{s}$ ); trees sway (approximately 15 $157 \mathrm{~m} / \mathrm{s}$ ). If the wind speed and direction were noticeably variable, we updated this information 158 during every instantaneous sample. We also noted whether the bird's shadow was obstructed 159 (e.g., by emergent vegetation) during every instantaneous sample. The orientation of the birds' 160 bodies and heads, and the orientation of the wind were estimated in the field with a handheld compass. Exact sun bearing and elevation were later retrieved from the National Oceanographic and Atmospheric Administration's online sun position calculator, based on the time recorded for each instantaneous sample in each observation. Also, the approximate latitude and longitude of each location were obtained from Google Earth. We were then able to calculate the estimated orientation differences between the birds and the sun, and between the birds and the wind, to use in analyses. After the final field season, we quantified error associated with estimating heron orientation. To do so, a field assistant placed a Great Blue Heron lawn ornament in 24 different directions and recorded its real orientation while the lead author (who made all compass measurements in the field) estimated each orientation from a distance of $20 \mathrm{~m}$, with the same binoculars that were used in the field (Nikon Monarch 3,10x42). Our estimations of body

171 orientations of a Great Blue Heron lawn ornament were within an average of $9.3^{\circ}\left(\mathrm{s} . \mathrm{d} .=7.5^{\circ}, \mathrm{N}\right.$ $172=24)$. Therefore, we believe our estimates of heron body orientation are sufficiently accurate to 173 test the hypotheses of interest in this study.

Using the Hydrolight ${ }^{\circledR}$ radiative transfer model (Mobley, 1998), we estimated absolute and relative glint in the green spectrum $(550 \mathrm{~nm})$. We defined relative green glint as green glint 
177 divided by the all incoming green light in the field of view (i.e., water-leaving radiance plus

178 radiance reflected by the sea surface). The relative measure is a type of signal-to-noise

179 measurement. We used green light exclusively, because we wanted our estimates of glint to be

180 conservative, in that they would maximize background brightness and minimize relative glint. In

181 general, green light penetrates furthest into coastal waters (Kirk, 2011), and is therefore the light

182 most available to be reflected by the seafloor, and exit the water as upwelling light. Therefore, in 183 comparison, the contribution of glint is lower relative to the upwelling light in the green

184 spectrum versus in other spectral regions.

186 We also used conservative but realistic values representing conditions in Florida, and conditions 187 for wild foraging herons, for all variables in $H y d r o l i g h t \circledR$, to obtain conservative estimates for 188 glint. We modeled reflectance for a light-colored sand (ooid), which is both typical of many 189 Florida coasts, but also creates high reflectance off of the sea floor, thus increasing the relative 190 signal of upwelling light as compared with glint. We used a medium value for light attenuation 191 in the water by indicating that light would attenuate by half for every meter below the sea surface 192 (McPherson et al., 2011). We also used a water depth of $28 \mathrm{~cm}$ based on multiple records of the 193 water depths in which herons forage in Florida (Powell, 1987; Bancroft, Gawlik \& Rutchey, 194 2002). We ran the model under two wind conditions: $5 \mathrm{~m} / \mathrm{s}$, and $10 \mathrm{~m} / \mathrm{s}$. We also ran each of 195 those models under two light conditions: where the sun was visible, and where it was obstructed 196 by clouds. 
198 To continue in our effort to gain conservative absolute and relative estimates of green glint, we

199 also only retrieved outputs from a viewing direction of $40^{\circ}$ to the nadir, because this viewing

200 direction minimizes the proportion of skylight reflected at the sea surface under multiple wind

201 speed scenarios (see Fig. 6 in Mobley, 1999).

203 We generated interpolated heat maps of absolute and relative glint in MATLAB (2015), using

204 estimates based on sun elevations of $0^{\circ}, 15^{\circ}, 30^{\circ}, 45^{\circ}, 60^{\circ}, 75^{\circ}$ and $90^{\circ}$ from the horizon.

205 Finally, we used two-sample t-tests to compare estimates of visual exposure to glint for each

206 heron body orientation with estimates of glint exposure that we would expect if heron orientation

207 were random, using coordinates generated from random.org, to test the prediction that herons

208 would orient in a manner that reduced visual exposure to glint.

210 All other statistical analyses were performed in R (R Core Team, 2013). To examine heron

211 orientation relative to sun position, we used only instantaneous samples where herons' heads

212 were oriented in the same direction as their bodies, and where the herons' shadows were cast

213 over water (i.e., unobstructed by emergent vegetation, and not cast onto land), and the sun was at

214 least partially visible. To test the prediction that herons would orient $135^{\circ}$ to the bearing of the

215 sun, we regressed the absolute difference between sun bearing and heron bearing (i.e. heron

216 orientation relative to sun bearing), against sun elevation, using generalized estimating equations

217 (Liang \& Zeger, 1986) with the "geepack" package in R (Højsgaard, Halekoh \& Yan, 2006). We

218 used sun elevation as the independent variable instead of time, so that we were comparing heron

219 orientations under consistent sun positions each day. To account for use of multiple observations 
220 for some individual herons, which are likely correlated, we used generalized estimating

221 equations (GEE). GEE, an extension of generalized linear models, is a statistical approach for

222 estimating regression parameters with clustered data (Liang \& Zeger, 1986). We used

223 "individuals" as grouping factors in our GEE model. We also used unstructured correlation

224 matrices because we were unsure of what, if any, kind of relationship there might be among

225 intra-individual data points. We then used the Wald-statistic to test the overall significance of the

226 regression. As there is no package to estimate power or effect size based on a Wald test, at

227 present, we estimated the effect size of our findings using a power analysis based on a

228 generalized least squares linear model of our data using the "pwr" package (Champely, 2015).

229 We similarly regressed the absolute value of the difference between wind and heron orientation

230 versus wind speed category; and the absolute value of the difference between sun and heron

231 orientation versus wind speed category as an ordered factor.

\section{Results}

234 Our prediction that herons would orient in a manner that suggested trading off reducing glint and 235 self-shadow in their strike zones was not supported. We detected no departures from random 236 orientation with respect to sun bearing in herons, across all sun elevations $\left(y=89.37^{\circ}-0.02 x\right.$;

$237 \mathrm{~W}=0.003 ; \mathrm{p}=0.96)$. This held true no matter whether we included the whole data set in the 238 analysis, or just the subset of the data from when both the sun and the heron's shadows were 239 visible (Fig. 3a-b). The calculated effect size when regressing heron orientation relative to sun

240 bearing versus sun elevation was miniscule $\left(\left[r^{2} /\left(1-r^{2}\right)\right]=\sim 0.0002\right)$. 
242 Overlaying our orientation data onto our heat maps displaying absolute and relative estimates of

243 green glint added further evidence that herons are not using body orientation to reduce visual

244 exposure to glint (Fig. 4). We decided to use only the heat maps we generated for $5 \mathrm{~m} / \mathrm{s}$ wind

245 speed for analyses because the heat maps generated for $10 \mathrm{~m} / \mathrm{s}$ wind appeared nearly identical.

246 There was no difference between the glint estimated at each heron orientation to the sun and glint

247 that would be experienced at random, either in absolute $(\mathrm{t}=1.76, \mathrm{p}=0.08)$ or relative estimates

248 of green glint $(t=1.55, \mathrm{p}=0.12)$ with a visible sun. With a completely obstructed sun, glint was

249 still no different from random for absolute $(\mathrm{t}=0.14, \mathrm{p}=0.89)$, or relative estimates of green glint

$250 \quad(\mathrm{t}=1.10, \mathrm{p}=0.27)$

In support of our last hypothesis, herons tended to face more into the wind with increasing wind speed. With each increase in ordered categorical wind speed, herons faced about $31.70^{\circ}(\mathrm{SE}=$ $\left.9.39^{\circ}\right)$ further toward the sun $(\mathrm{W}=114, \mathrm{p}=0.0007)($ Fig. 5$)$.

\section{Discussion}

Our data provide strong evidence that herons are not using body orientation with respect to sun position as a behavioral mechanism for reducing glint in their strike zone. Herons, when foraging through the highly reflective air-water interface, are not avoiding orienting in directions with the highest estimated exposure to glint, whether in absolute terms, or relative to incoming light, and they are not trading off glint and shadow in their strike zones. 
263 Our data also showed that as wind speed increased, herons tended to face more head-on into the 264 wind. In retrospect, this is not surprising. One likely explanation for orienting to the wind is that

265 herons are orienting for thermoregulatory purposes. Facing into the wind has been shown to

266 decrease heat loss in birds (e.g., Fortin Larochelle \& Gauthier, 2000).

Herons, and other cross-media hunters, may compensate for glint in other ways. Krebs \& Partridge (1973) hypothesized that Great Blue Herons tilt their heads and long necks toward the sun - in a foraging behavior known as "head-tilting" (Meyerriecks 1962) - to effectively shift a perceived area of glare out of their intended strike path. However, their idea was not fully tested, and further research is required to assess whether herons are head-tilting to compensate for glint effects, or has a different function. Relatedly, differences in head placement during foraging might account for some variability in heron body orientation with respect to sun elevation. Future research could investigate the direction of viewing, and eye movement in relationship to 276 glint.

Because light that is reflected from water surfaces is polarized, some form of polarization vision could be useful to cross-media hunters. Theoretically, there are at least two ways to filter polarized light: before the image is projected onto the retina, or after. For polarized light to be filtered prior to reaching the retina, herons would need an anatomical feature capable of excluding it (as polarized sunglasses would). However, we are unaware of any evidence for such anatomical features in any natural visual systems. For polarized light to be filtered after reaching

284 the retina, we would suggest some neurological capability that allows herons to detect, and 
285 subsequently ignore the polarized light as "noise", similar to how we would filter out a din of

286 many voices while conversing with a friend in a crowded restaurant. This possibility seems much

287 more likely. There is considerable evidence that animals across many taxa can see patterns of

288 light polarization, including some behavioral evidence in birds (reviewed in Muheim, 2011). We

289 suggest that behavioral studies designed to detect whether avian cross-media predators exhibit

290 polarized light sensitivity would be fruitful for understanding the ability of these birds to hunt

291 successfully in the face of intense glint.

Herons may be a good system in which to look for a mechanism for polarization vision in birds

because they do not seem to be behaviorally compensating for glint. To date, we only have some very basic details about herons' visual anatomy. In Great Blue Herons, fine structures of the pecten (Braekevelt, 1991), rods and cones (Braekevelt, 1994) and cone pigments (Braekevelt \& Young, 1994) have been studied. Their rod to cone ratio is also documented; it is $0.6: 1$, which puts them in between the diurnal herons (e.g., the Tricolored Heron, Egretta tricolor, has a rod to cone ratio of $0.3: 1$ ) and the nocturnal herons (e.g., the Yellow-crowned Night Herons, Nycticorax violaceus, has a 2.3:1 rod to cone ratio; Rojas et al., 1999). Generally, higher rod to cone ratios produce better night vision than lower rod to con ratios (Rojas et al., 1999). In Great book, in which the basic macrostructure of the pecten, and the "dominant color" of the fundus were described (Wood, 1917). 
306

307

308

309

310

311

312

313

314

315

316

317

318

320

321

322

323

324

325

326

Although we have suggested some avenues of study to investigate other potential behavioral or anatomical mechanisms for reducing glint exposure in herons, it is possible that there are crossmedia predators that do use body orientation to mitigate effects of glint. There is some anecdotal evidence for this behavior in Brown Pelicans (Pelecanus occidentalis) and terns (Carl, 1987; Supporting Information). Therefore, we suggest further study of body orientation relative to sun bearing in these, and other, plunge-diving birds.

Lastly, we suggest continuing to use radiative transfer modeling to better understand the light conditions that air-to-water cross-media predators face while foraging. This new tool might also be useful for re-examining work from previous studies, for example on the physical conditions that affect foraging success in piscivorous birds (e.g., Grubb, 1977; Bovino \& Burtt, 1979; Carl, 1987). Understanding the conditions under which birds view their prey will lead to deeper understanding of their visual and behavioral ecology.

\section{Conclusions}

In this study, we tested the hypothesis that foraging herons would orient away from the sun to avoid experiencing glare due to sunlight reflecting from surfaces of the water bodies in which they hunt. Field observations of heron body orientation, along with our estimations of sun glint via radiative transfer modeling provided evidence against our hypothesis; herons did not tend to orient in a manner that reduced their exposure to glint, but rather oriented to face the wind at higher wind speeds. Radiative transfer modeling, a tool from optical oceanography, was useful 
327 for investigating visual and behavioral ecology in this air-to-water foraging system, and should

328 be considered in similar studies.

\section{Acknowledgements}

331 We are grateful to the Smithsonian Marine Station, where a portion of these data was collected

332 while HMB was working under the advisement of C.S. McKeon. For edits and helpful

333 commentary, we are also grateful to T.W. Cronin, the entire Ornithology Group at the University

334 of Connecticut, Andrew Moiseff, Eric Schultz, the late Eldridge Adams, and reviewers.

\section{References}

Bancroft GT, Gawlik DE, Rutchey K. 2002. Distribution of wading birds relative to vegetation and water depths in the northern Everglades of Florida, USA. Waterbirds 25:265-391.

Bovino RR, Burtt EH. 1979. Weather-dependent foraging of great blue herons (Ardea herodias). Auk 96:628-630.

Braekevelt CR. 1991. Electron microscopic observations on the pecten of the great blue heron (Ardea herodias). Histology and Histopathology 6:345-351.

Braekevelt CR. 1994. Retinal photoreceptor fine structure in the great blue heron (Ardea herodias). Anatomia, Histologia, Embryologia 23:281-292. DOI: 10.1111/j.14390264.1994.tb00477.x.

Braekevelt CR, Young DLW. 1994. Retinal pigment epithelial fine structure in the great blue heron (Ardea herodias). Anatomia, Histologia, Embryologia 23:293-300. 
348 Carl RA. 1987. Age-class variation in foraging techniques by brown pelicans. The Condor 89:525-533.

350

351

352

353

355

356

357

358

360

361

362

363

364

365

366

367

368

Champely S. 2015. pwr: Basic functions for power analysis. R package version 1.1-2. http://CRAN.R-project.org/package=pwr

Fortin D, Larochelle J, Gauthier G. 2000. The effect of wind, radiation and body orientation on the thermal environment of greater snow goose goslings. Journal of Thermal Biology 25:227-238. DOI: 10.1016/S0306-4565(99)00028-5.

Forward RB. 1977. Occurrence of a shadow response among brachyuran larvae. Marine Biology 39: $331-341$.

Grubb TJ. 1977. Weather-dependent foraging in ospreys. Auk 94: 146-149.

Hochberg, E.J., Mobley, C.D., Park, Y., Goodman, J., Turpie, K.R., Gao, B.-C., Bruce, C.F., Green, R.O., Knox, R.G., Muller-Karger, F.E., Middleton, E.M., Minnett, P.J., Gentemann, C., Oaida, B.V., Zimmerman, R.C., Turner, W., Ungar, S. 2011. HyspIRI Sunglint Subgroup Report.

Højsgaard S, Halekoh U, Yan J. 2006. The R Package geepack for generalized estimating equations. Journal of Statistical Software 15:1-11.

Huveneers C, Holman D, Robbins R, Fox A, Endler JA, Taylor AH. 2015. White sharks exploit the sun during predatory approaches. American Naturalist 185:562-570. DOI: $10.1086 / 680010$.

King DT, LeBlanc D. 1995. Foraging behaviors of snowy egrets (Egretta thula) and yellowcrowned night-herons (Nyctanessa violacea). Colonial Waterbirds 18:224-225. 
369 Kirk JTO. 2011. Light and photosynthesis in aquatic ecosystems, $3^{\text {rd }}$ edn. New York: Cambridge $370 \quad$ University Press.

371 Krebs JR, Partridge B. 1973. Significance of head-tilting in the great blue heron. Nature 372 242:533-535. DOI: $10.1038 / 242533 \mathrm{a} 0$.

373

374

375

376

377

378

379

380

381

382

383

384

385

386

387

388

389

Liang KY, Zeger SL. 1986. Longitudinal data analysis using general linear models. Biometrika 73:13-22. DOI: 10.1093/biomet/73.1.13.

MATLAB and Statistics Toolbox Release 2015a. 2015. The MathWorks, Inc., Natick.

McNeil R, Benoît R, DesGranges J-L. 1993. Daytime and nighttime activity at a breeding colony of great blue herons in a nontidal environment. Canadian Journal of Zoology 71:10751078. DOI: $10.1139 / \mathrm{z} 93-145$.

McPherson L, Hill VJ, Zimmerman RC, Dierssen HM. 2011. The optical properties of greater Florida Bay: implications for seagrass abundance. Estuaries and Coasts 34:1150-1160. DOI 10.1007/s12237-011-9411-9 .

Meyerriecks, A.J. (1962) Diversity typifies heron feeding. Specialized foraging techniques permit species to coexist. Natural History, 71, 48-59.

Mobley CD. 1999. Estimation of the remote-sensing reflectance from above-surface measurements. Applied Optics 38:7442-7455. DOI: 10.1364/AO.38.007442.

Mobley CD. 1998. Hydrolight 4.0 Users Guide. Sequoia Scientific Inc., Mercer Island.

Muheim R. 2011. Behavioral and physiological mechanisms of polarized light sensitivity in birds. Philosophical Transactions of the Royal Society B 366:763-771. DOI: 10.1098/rstb.2010.0196. 
390 Muheim R, Phillips JB, Åkeesson S. 2006. Polarized light cues underlie compass calibration in migratory songbirds. Science 313:837-839. DOI: 10.1126/science.1129709.

392

393

394

395

396

397

398

399

400

401

402

403

404

405

406

407

408

409

Orr Y. 1970. Temperature Measurements at the Nest of the Desert Lark (Ammomanes deserti deserti). The Condor 72:476-478.

Penacchio O, Cuthill IC, Lovell G, Ruxton GD, Harris JM. 2015. Orientation to the sun by animals and its interaction with crypsis. Functional Ecology 29:1165-1177. DOI: $10.1111 / 1365-2435.12481$.

Powell GVN. 1981. Habitat use by wading birds in a subtropical estuary: implications of hydrology. Auk 104:740-749.

Preisendorfer, RW., Mobley, C.D. 1986. Albedos and glitter patterns of a wind-roughened sea surface," Journal of Physical Oceanography 16:1293-1316.

Prum RO, Berv JS, Dornburg A, Field DJ, Townsend JP, Lemmon EM, Lemmon AR. 2015. A comprehensive phylogeny of birds (Aves) using targeted next-generation DNA sequencing. Nature 526:569-573.

R Core Team. 2013. R: A language and environment for statistical computing. R Foundation for Statistical Computing, Vienna. http://www.R-project.org/.

Roberts A. 1978. Pineal eye and behavior in Xenopus tadpoles. Nature 273:774-775.

Rojas LM, McNeil R, Cabana T, Lachapelle P. 1999. Behavioral, morphological and physiological correlates of diurnal and nocturnal vision in selected wading bird species. Brain, Behavior and Evolution 53:227-242. DOI: 10.1159/000006596. 
410 Signoroni, A., Conte, M., Plutino, A. and Rizzi, A. 2020. Spatial-Spectral Evidence of Glare 411 Influence on Hyperspectral Acquisitions. Sensors, 20:4374.

412 Walsberg GE. 1993. Thermal consequences of diurnal microhabitat selection in a small bird. $413 \quad$ Ornis Scandinavica 24:174-182.

414 Wood CA. 1917. The fundus oculi of birds especially as viewed by the ophthalmoscope. 415 Chicago: The Lakeside Press.

416 Yosef R, Zduniak P, Tryjanowski P. 2012. Unmasking Zorro: Functional importance of the 417 facial mask in the Masked Shrike (Lanius nubicus). Behavioral Ecology 23:615-618. $418 \quad$ DOI: $10.1093 /$ beheco/ars005.

419 Yoshizawa M, Jeffery WR. 2008. Shadow response in the blind cavefish Astyanax reveals $420 \quad$ conservation of a functional pineal eye. The Journal of Experimental Biology 211:292299. DOI:10.1242/jeb.012864. of skylight. Optics Express 25, A1-A13. 
Figure 1

Schematic representation of an overhead view of a foraging heron.

We predicted that herons would orient generally away from the sun to minimize visual exposure to glint; if they also avoid casting shadows over prey (which alert prey to their presence), we predict that they will orient at about $135^{\circ}$ away from the bearing of the sun.

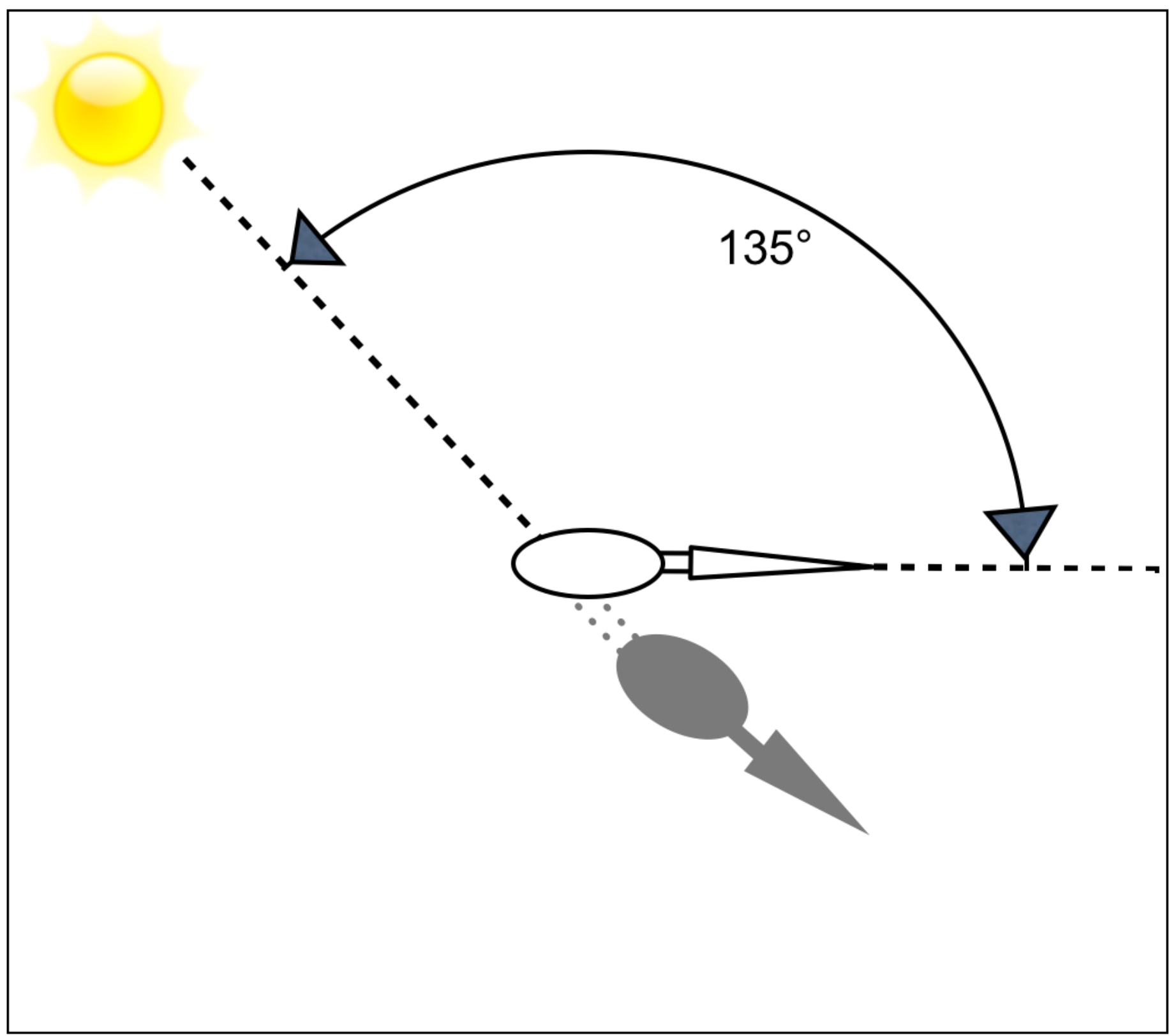


Figure 2

Locations at which herons were observed in southern Florida, USA.

Circles indicate where data were collected. Some circles overlap more than one sampling location. Image Credit: The map was cropped from the original, "Administrative Map of Florida," created by Eric Gaba, via Wikimedia Commons (c) 2008 (user ID: Sting, CC BY 3.0).

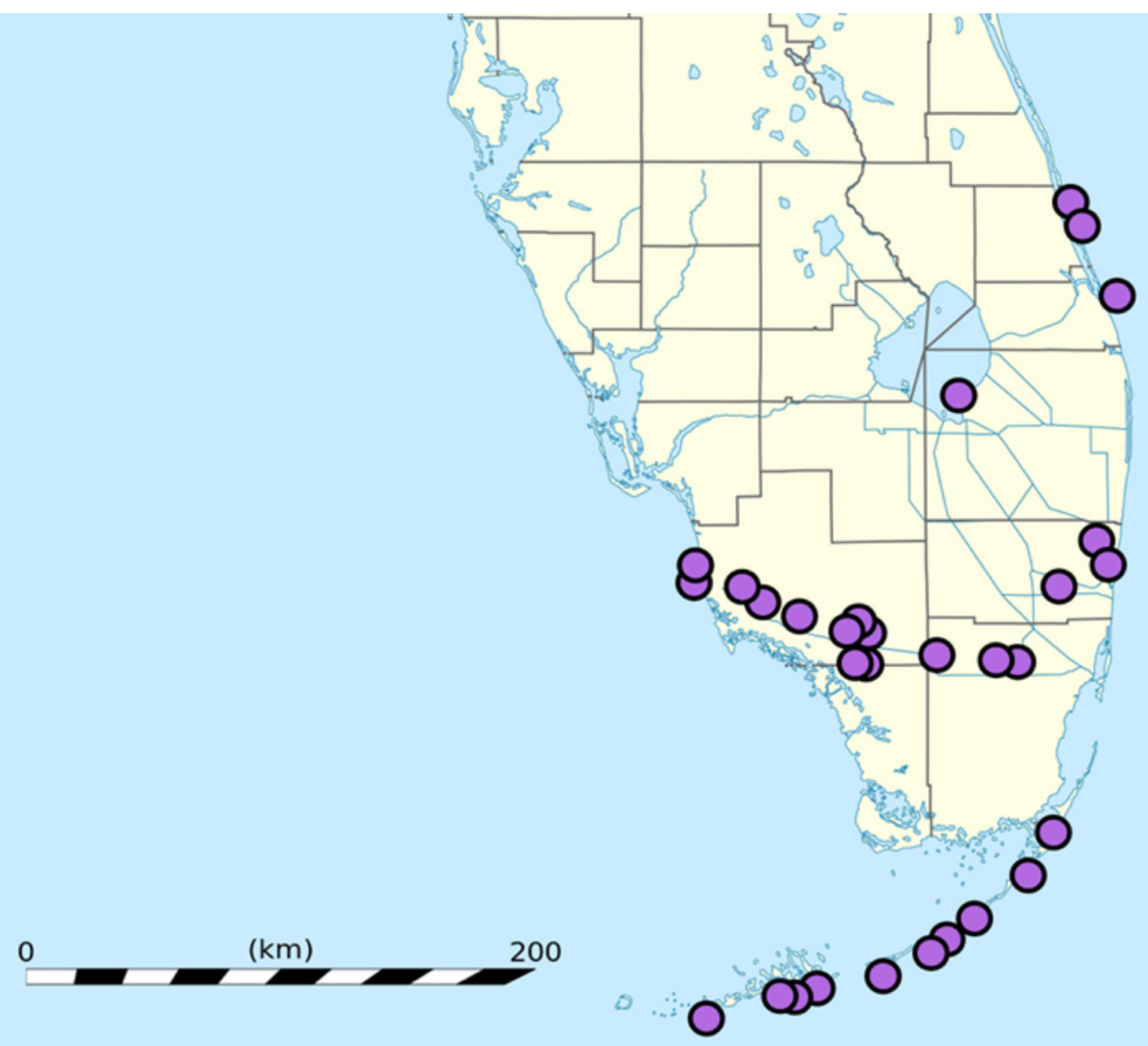




\section{Figure 3}

Scatterplots of our data, using points where heron's head and body orientations were in parallel.

In both graphs, $0^{\circ}$ on the $x$-axis indicates that the sun is on the horizon, and $90^{\circ}$ indicates that the sun is overhead. On the $y$-axis, $0^{\circ}$ indicates that the heron was facing directly into the sun, and $180^{\circ}$ indicates that the heron was facing opposite to the sun. a. Using the whole data set, note that heron orientation with respect to sun position does not support our predictions, but rather appears random $(p=0.95)$. b. Using only data points where the sun was unobstructed (e.g., by clouds) and the heron's shadow was unobstructed (e.g., by emergent vegetation) thins the data substantially, but does not change the overall lack of pattern $(p=0.96)$. 


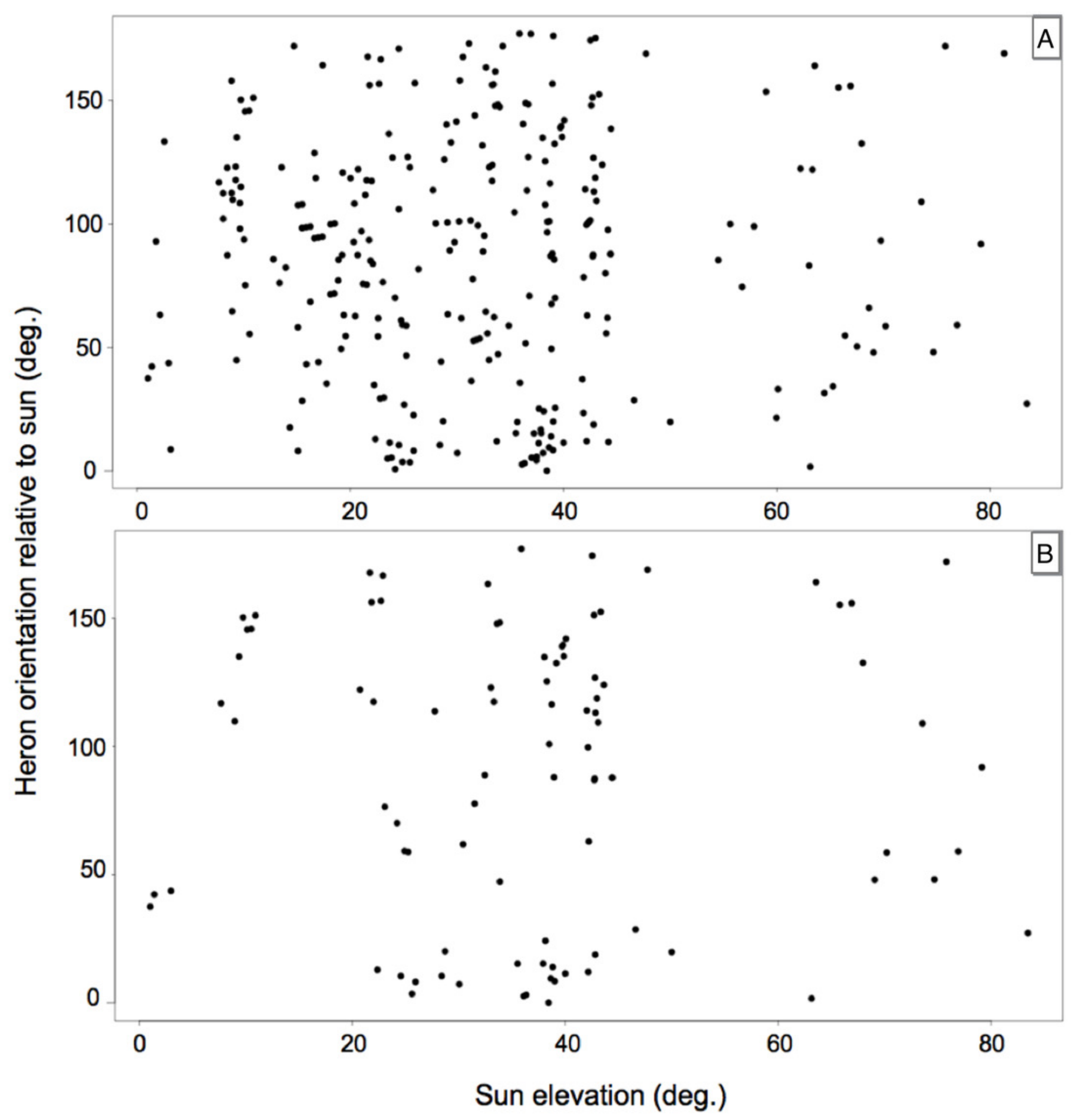




\section{Figure 4}

Heat maps that indicate measures of green sun glint $(550 \mathrm{~nm})$ directed at the viewer when wind is $5 \mathrm{~m} / \mathrm{s}$, by absolute $(a, b)$ and relative $(c, d)$ measures.

Our orientation data from Fig. 3b are superimposed on these heat maps by sun visibility: sun visible (left) and sun obstructed (right). Note that herons are orienting randomly, and they are foraging in "hot spots" where glint is maximized. (Heat maps for wind speeds of $10 \mathrm{~m} / \mathrm{s}$ were nearly identical, and are not shown here.)
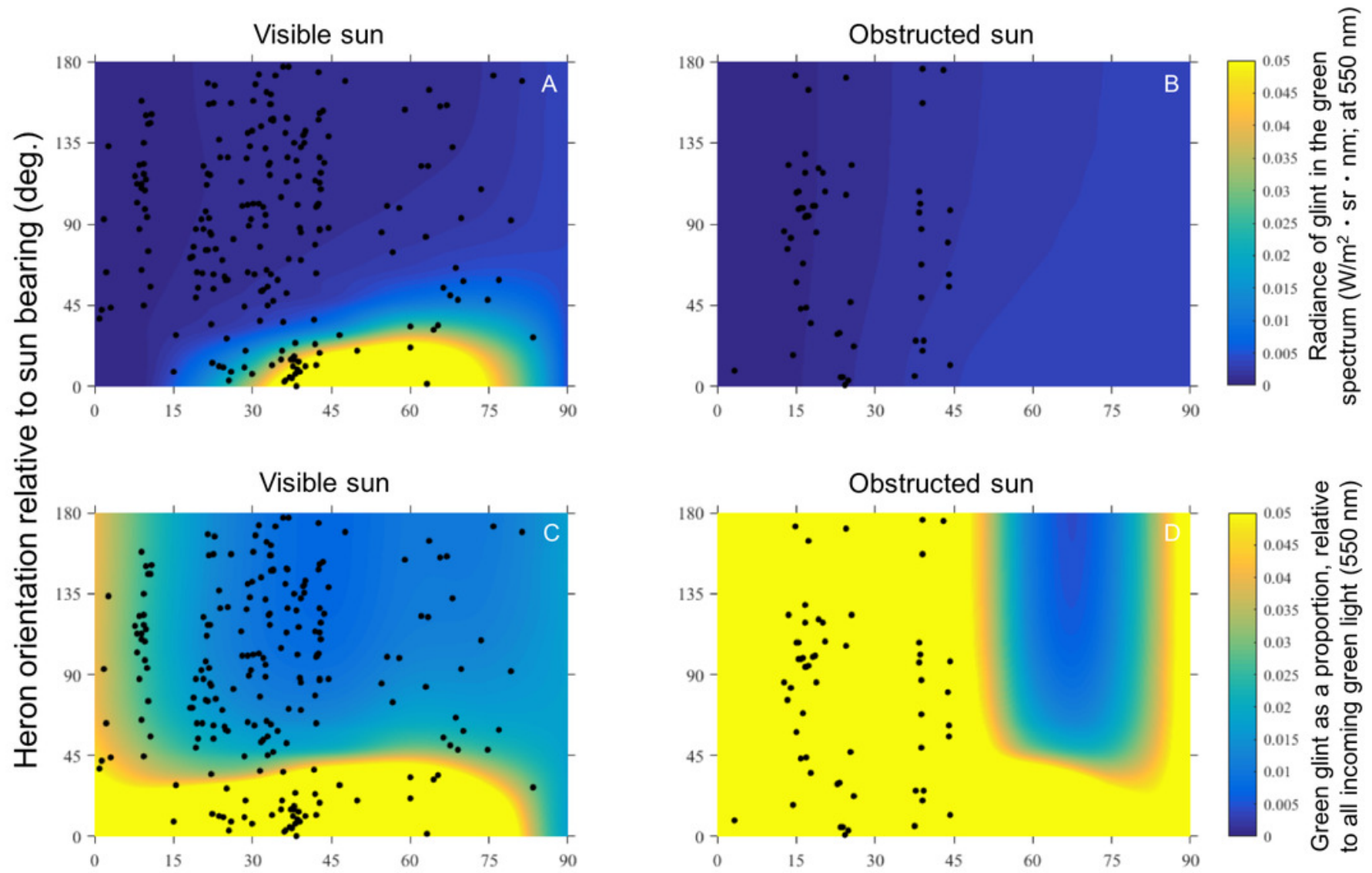

Sun elevation (deg.) 
Figure 5

Box plot of heron orientation with respect to the bearing of the wind by wind speed category $(0=$ calm or $\sim 0 \mathrm{~m} / \mathrm{s} ; 1=$ leaves rustle or $\sim 5 \mathrm{~m} / \mathrm{s} ; 2=$ branches sway or $\sim 10$ $\mathrm{m} / \mathrm{s} ; 3=$ trees sway or $\sim 15 \mathrm{~m} / \mathrm{s}$ ).

On the $y$-axis, $0^{\circ}$ indicates that the heron was facing directly into the wind, and $180^{\circ}$ indicates that it was facing opposite to the wind. With each increase in ordered categorical wind speed, herons faced about $31.70^{\circ}\left(\mathrm{SE}=9.39^{\circ}\right)$ further toward the sun $(\mathrm{W}=114, \mathrm{p}=$ $0.0007)$.

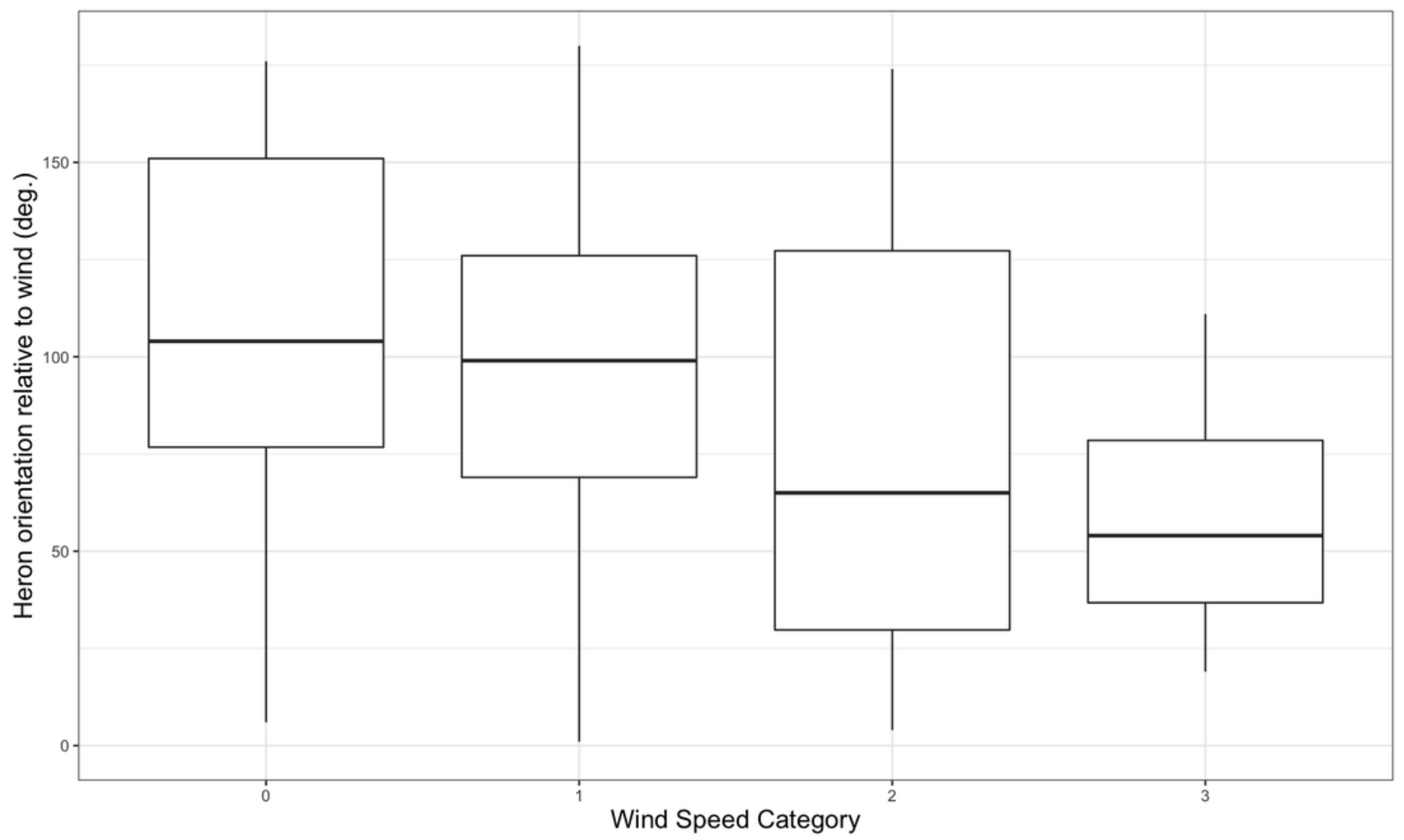

